\title{
Desenvolvimento inicial e partição de biomassa de Brosimum rubescens Taub. (Moraceae) sob diferentes níveis de sombreamento ${ }^{1}$
}

\author{
Beatriz Schwantes Marimon ${ }^{2,5}$, Jeanine Maria Felfili ${ }^{3}$ Ben Hur Marimon Júnior ${ }^{2}$, \\ Augusto César Franco ${ }^{4}$ e Christopher William Fagg 3
}

Recebido em 19/07/2007. Aceito em 26/12/2007

\begin{abstract}
RESUMO - (Desenvolvimento inicial e partição de biomassa de Brosimum rubescens Taub. (Moraceae) sob diferentes níveis de sombreamento). Florestas monodominantes de Brosimum rubescens Taub. (Moraceae) ocorrem na zona de transição Cerrado/Amazônia e encontram-se ameaçadas pela extração da madeira. Dentre as possíveis causas de monodominância destaca-se a disponibilidade de luz, de modo que o objetivo deste trabalho foi testar os efeitos no crescimento e na assimilação de $\mathrm{CO}_{2}$ de diferentes níveis de sombreamento em condições naturais e em viveiro. Em viveiro, os tratamentos foram 0, 30, 50,70 e $90 \%$ de sombreamento e na floresta foram avaliadas plantas jovens crescendo sob o dossel e em clareira. A taxa de assimilação de $\mathrm{CO}_{2}$ em resposta a variações na intensidade luminosa foi medida em plantas jovens sob três condições de sombreamento. As plantas que cresceram sob o dossel fechado apresentaram taxas de crescimento relativo menores do que aquelas que cresceram na clareira. Aos 21 meses, o maior valor de massa seca total ( $9,46 \mathrm{~g})$ foi encontrado sob $50 \%$ de sombreamento, representando um acúmulo de biomassa $144 \%$ superior ao tratamento sob $90 \%$. Em todos os tratamentos e amostragens, a partição foi massa seca da raiz $>$ folhas $>$ caule. A menor taxa fotossintética máxima $\left(\mathrm{A}_{\text {máx }}=3,46 \mu\right.$ mol m $\left.{ }^{2} \mathrm{~s}^{-1}\right)$ foi observada para $90 \%$ de sombreamento e a maior $\left(\mathrm{A}_{\text {máx }}=7,89 \mu \mathrm{mol} \mathrm{m} \mathrm{m}^{-2} \mathrm{~s}^{-1}\right)$ foi registrada sob $30 \%$ de sombreamento. Clareiras provavelmente desempenham um papel importante na manutenção da monodominância, uma vez que $B$. rubescens apresentou plasticidade para diferentes condições de luminosidade e maior crescimento nos níveis intermediários de sombreamento.
\end{abstract}

Palavras-chave: análise de crescimento, floresta monodominante, fotossíntese, luz, Mato Grosso

\begin{abstract}
Initial development and biomass allocation in seedlings of Brosimum rubescens Taub. (Moraceae) at different shading levels). Monodominant forests of Brosimum rubescens Taub. (Moraceae) occur at the Cerrado/Amazonia boundary and are threatened by logging. Light is considered an important determinant for monodominance in forests, so the aim of this study was to analyze initial growth at shading levels of $0,30,50,70$ and $90 \%$ in the nursery, in a forest gap, and also at a closed canopy site. Photosynthesis was measured in seedlings at three shading levels. Seedlings under a closed canopy showed lower relative growth rates in comparison to seedlings growing in a nearby gap. At 21 months of age, the highest total dry mass of $9.46 \mathrm{~g}$ was measured at 50\% shading. This represents a biomass accumulation of $144 \%$ over that found at $90 \%$ shading. For all treatments in every assessment the partitioning was dry matter of roots $>$ leaves $>$ stems. The lowest maximum photosynthesis rate $\left(\mathrm{A}_{\max }=3.46 \mu \mathrm{mol} \mathrm{m}^{-2} \mathrm{~s}^{-1}\right)$ was recorded at $90 \%$ shading and the highest $\left(\mathrm{A}_{\max }=7.89 \mu \mathrm{mol} \mathrm{m} \mathrm{m}^{-2} \mathrm{~s}^{-1}\right)$ was recorded at $30 \%$ shading. Gaps seem to play an important role in maintaining monodominance since $B$. rubescens showed some plasticity regarding light conditions and grew better at intermediate shading levels.
\end{abstract}

Key words: growth analysis, monodominant forest, photosynthesis, light, Mato Grosso

\section{Introdução}

A monodominância em florestas tropicais, em que uma única espécie forma 50 a $100 \%$ da biomassa florestal arbórea (Connell \& Lowman 1989) é um fenômeno relativamente raro nos trópicos onde, em geral, as florestas contêm muitas espécies arbóreas com poucos indivíduos por espécie. Entretanto, apesar de raras, florestas monodominantes são encontradas em regiões tropicais de todos os continentes (Connell \& Lowman 1989; Nascimento et al. 1997b; Read et al. 2000; Torti et al. 2001; Marimon et al. 2001a; b; Marimon \& Felfili 2006).

Compreender os processos que mantêm a monodominância pode ser útil na busca de explicações sobre a coexistência das muitas espécies de árvores nas florestas tropicais (Richards 1996). A disponibilidade de luz em florestas tropicais parece ser um dos fatores

\footnotetext{
1 Parte da Tese de Doutorado da primeira Autora, Programa de Pós-Graduação em Ecologia, C. Postal 04457, 70919-970 Brasília, DF, Brasil

2 Universidade do Estado de Mato Grosso, Campus Universitário de Nova Xavantina, Departamento de Ciências Biológicas, C. Postal 08, 78690-000 Nova Xavantina, MT, Brasil

3 Universidade de Brasília, Departamento de Engenharia Florestal, C. Postal 04357, 70900-900 Brasília, DF, Brasil (felfili@unb.br)

4 Universidade de Brasília, Departamento de Botânica, C. Postal 04457, 70904-970 Brasília, DF, Brasil

5 Autor para correspondência: biamarimon@hotmail.com, biamarimon@yahoo.com.br
} 
críticos no desenvolvimento das plântulas (Denslow 1980), ressaltando-se a importância das clareiras na criação de diferentes níveis de sombreamento no subbosque. A heterogeneidade espacial e temporal do regime luminoso afeta a sobrevivência e o desenvolvimento das plantas (Denslow et al. 1990; Brown \& Whitmore 1992; Clark \& Clark 1992; Agyeman et al. 1999) e, portanto, a dinâmica florestal. Diversos trabalhos apresentam discussões detalhadas sobre a influência de diferentes níveis de irradiação solar no crescimento e desenvolvimento de plântulas de espécies de florestas tropicais chuvosas (Augspurger 1984; Poorter 1999; Agyeman et al. 1999) e florestas de galeria (Rezende et al. 1998; Felfili et al. 1999; 2001). Entretanto, estudos desta natureza são muito escassos para florestas monodominantes. Green \& Newbery (2001) estudaram a regeneração de uma espécie monodominante na África Central e verificaram que o aumento de 0,22 para $36 \%$ dos níveis de irradiação solar incidente estimulou o aumento da biomassa das plântulas da espécie.

$\mathrm{O}$ conhecimento da capacidade de tolerância à sombra das espécies é fundamental para se determinar o padrão de sistemas silviculturais a serem adotados no manejo de uma floresta (Kiama \& Kiyiapi 2001), prática necessária para áreas que sofrem intensa ação antrópica, especialmente na região neotropical. Muitas manchas de floresta monodominante de Brosimum rubescens Taub. (Moraceae) ocorriam na região leste do Estado de Mato Grosso na zona de transição entre o Cerrado e a Floresta Amazônica. Atualmente são raras devido à intensa exploração por fazendeiros e madeireiros, que utilizam a madeira de grande durabilidade dessa espécie, especialmente para a confecção de pilares e postes para cercas. Não existem ações efetivas visando a preservação das áreas ainda intactas ou a recuperação das perturbadas. Dentre as poucas manchas remanescentes, algumas se encontram em reservas indígenas. Os índios Xavante demonstram especial interesse pela espécie, utilizando o cerne da madeira para confeccionar bordunas (arma em forma de bastão) e para construções, além de usar seus frutos como alimento e como atrativo para a fauna silvestre durante suas expedições de caça. Informações sobre a estrutura, composição florística, chuva de sementes, características ambientais e etnobotânica de duas manchas representativas desta floresta estão disponíveis em Marimon \& Felfili (2000; 2001; 2006) e Marimon et al. (2001a; b).

Devido à importância econômica e sócio-ambiental de Brosimum rubescens e à iminente ameaça de desaparecimento das manchas remanescentes desta floresta monodominante, é imprescindível que se desenvolvam estudos sobre os processos envolvidos no crescimento e desenvolvimento das plantas jovens dessa espécie, restritas ao sub-bosque, geralmente ainda retendo os cotilédones. Considerando-se que a disponibilidade de luz em florestas tropicais parece ser um dos fatores críticos para o desenvolvimento das plântulas (Denslow 1980), é necessário testar a espécie sob diferentes níveis de sombreamento, no sentido de embasar modelos e estratégias de recuperação, conservação e manejo sustentado desta floresta, além de verificar se existe alguma relação entre a monodominância e a abertura de clareiras.

Observações efetuadas entre 1996 e 2004 na floresta de Brosimum rubescens mostraram que a ocorrência de plantas jovens no sub-bosque da floresta é extremamente abundante, formando banco de plântulas, mas a ocorrência de indivíduos com altura superior a $2 \mathrm{~m}$ e DAP $\leq 5 \mathrm{~cm}$ (arvoretas) é muito rara (Marimon et al. 2001a; b; Marimon \& Felfili 2006). Segundo Augspurger (1984) e Fordyce et al. (2000), quando arvoretas estão ausentes em condições de sombreamento, infere-se que a espécie requer a ocorrência de clareiras para garantir o sucesso de sua regeneração. Assim, formulou-se a hipótese de que B. rubescens apresenta plantas jovens persistentes, com crescimento muito lento e taxa fotossintética baixa, até o surgimento de clareiras que permitam o seu desenvolvimento com taxas mais aceleradas de crescimento.

Neste contexto, o objetivo do presente trabalho foi testar o efeito dos níveis de sombreamento sobre o desenvolvimento de plantas jovens (altura $<30 \mathrm{~cm}$ ) de Brosimum rubescens em condições naturais e em viveiro, simulando níveis de luminosidade que podem ser encontrados na floresta. Além disso, determinou-se a taxa de assimilação de $\mathrm{CO}_{2}$ em resposta a variações na intensidade luminosa nas plantas expostas a diferentes níveis de luminosidade em viveiro, para examinar a capacidade de aclimatação do metabolismo de carbono a diferentes níveis de sombreamento.

\section{Material e métodos}

A espécie - Brosimum rubescens apresenta distribuição descontínua nos Estados de Mato Grosso, Pará, Tocantins e Amazonas e em diversos países no norte da América do Sul e na América Central (Berg 1972). Na região leste de Mato Grosso e sul do Pará ocorrem extensas manchas de floresta monodominante dessa espécie (Marimon et al. 2001a; b). A área selecionada para estudo está localizada na Fazenda Vera Cruz (antiga Faz. Eldorado), retiro Pau Brasil (1450'47'S e 5208'37'W), município de Nova Xavantina, Mato Grosso.

Brosimum rubescens é uma espécie monóica, com indivíduos de 20 a $35 \mathrm{~m}$ de altura e 20 a $50 \mathrm{~cm}$ de DAP 
(diâmetro à altura do peito), com fuste reto e cilíndrico na fase madura. Frutifica, em geral, entre junho e setembro, sendo as sementes globosas, com cerca de $1,5 \mathrm{~cm}$ de comprimento e $900 \mathrm{mg}$ de massa seca (Marimon \& Felfili 2006). A densidade básica da madeira é de $0,92 \mathrm{~g} \mathrm{~cm}^{-3}$, com elevada resistência natural do cerne ao ataque de fungos e insetos (Nascimento et al. 1997a). A espécie é semidecídua, perdendo suas folhas durante todo o ano, com um pico na época da seca (B.S. Marimon, dados não publicados). São poucas as informações disponíveis na literatura sobre o status sucessional da espécie; porém, observações preliminares feitas por Marimon et al. (2001a; b) sugerem que ela seja sucessional secundária, com crescimento lento sob condições sombreadas e mais rápido em clareiras, conforme o modelo proposto por Swaine \& Whitmore (1988).

Experimentos em viveiro - Foram conduzidos no viveiro florestal da Fazenda Água Limpa (FAL) da Universidade de Brasília entre setembro/2001 e junho/2003. A FAL localiza-se a $15^{\circ} 56^{\prime} 14^{\prime \prime}$ 'S e $47^{\circ} 46^{\prime} 08^{\prime \prime} \mathrm{W}$, a uma altitude de $1.100 \mathrm{~m}$. O clima é do tipo Aw, segundo a classificação de Köppen, apresentando duas estações bem definidas, uma seca de maio a setembro e uma chuvosa de outubro a abril (Felfili et al. 1999), com precipitação média anual de $1.500 \mathrm{~mm}$ no período estudado.

As sementes de Brosimum rubescens foram coletadas em julho/2001, na floresta monodominante da Fazenda Vera Cruz, e semeadas no viveiro da FAL em setembro/2001 em sacos de polietileno preto de $15 \times 30 \mathrm{~cm}$, com perfurações laterais. O substrato utilizado foi o solo de uma floresta de galeria da Reserva Ecológica do Roncador (Brasília, DF), coletado à profundidade de 0 a $20 \mathrm{~cm}$. Experimentos preliminares mostraram que este foi o substrato no qual as plantas jovens de $B$. rubescens apresentaram melhor crescimento (C.W. Fagg, dados não publicados). Os resultados das análises químicas do substrato estão apresentados na Tab. 1.

Foram semeadas duas sementes em cada saco e após a emergência foi mantida apenas uma planta por saco. Antes de iniciar os tratamentos as plantas foram mantidas em casa de vegetação, sob $70 \%$ de sombreamento. Para minimizar a mortalidade, a seleção e o monitoramento das plantas tiveram início após aparecerem no mínimo duas folhas em cada indivíduo. Cinco meses após a semeadura as plantas jovens nãoestabelecidas e ainda retendo os cotilédones foram transferidas para os locais cujas condições de sombreamento definiram os tratamentos e deu-se início à fase de monitoramento. Foram realizadas irrigações por aspersão, pela manhã e à tarde, durante todo o período experimental.
Tabela 1. Análise química do solo de floresta de galeria utilizado para a produção de mudas de Brosimum rubescens Taub. em viveiro $(n=1)$. Solo bem drenado, às margens do Córrego Monjolo, Reserva Ecológica do IBGE, DF, Brasil. Análises efetuadas no Laboratório de Solos do Departamento de Ecologia da Universidade de Brasília.

\begin{tabular}{lr}
\hline Características & Teores \\
\hline $\mathrm{pH}\left(\mathrm{H}_{2} \mathrm{O} ; 1: 2,5\right)$ & 5,42 \\
$\mathrm{pH}(\mathrm{KCl} ; 1: 2,5)$ & 4,54 \\
$\mathrm{Al}\left(\mathrm{cmol}_{\mathrm{c}} \mathrm{kg}^{-1}\right)$ & 1,18 \\
$\mathrm{Ca}\left(\mathrm{cmol}_{\mathrm{c}} \mathrm{kg}^{-1}\right)$ & 2,39 \\
$\mathrm{Mg}\left(\mathrm{cmol}_{\mathrm{c}} \mathrm{kg}^{-1}\right)$ & 1,20 \\
$\mathrm{~K}\left(\mathrm{cmol}_{\mathrm{c}} \mathrm{kg}^{-1}\right)$ & 0,32 \\
$\mathrm{P}\left(\mathrm{mg} \mathrm{dm}^{-3}\right)$ & 0,60 \\
$\mathrm{Fe}\left(\mathrm{mg} \mathrm{dm}^{-3}\right)$ & 36,20 \\
$\mathrm{Mn}\left(\mathrm{mg} \mathrm{dm}^{-3}\right)$ & 17,90 \\
$\mathrm{~N}(\%)$ & 0,39 \\
Matéria orgânica $\left(\mathrm{dag} \mathrm{kg}^{-1}\right)$ & 3,44
\end{tabular}

$\mathrm{O}$ experimento consistiu de cinco tratamentos representados pelos níveis de sombreamento, com 50 repetições por tratamento, sendo que a alocação das parcelas experimentais foi aleatória (Sokal \& Rolf 1981). As plantas foram submetidas aos mesmos tratamentos adotados por Felfili et al. (1999), sendo 1) 0\% de sombreamento, com exposição das plantas a pleno sol, representando a condição extrema de uma área totalmente degradada; 2) $30 \%$ de sombreamento, obtidos em casa de vegetação com cobertura lateral e superior de sombrite verde, representando uma condição intermediária entre pleno sol e $50 \%$ de sombreamento, com DFFA (Densidade de Fótons Fotossinteticamente Ativos) de cerca de $70 \%$ em relação ao obtido a pleno sol; 3) 50\% de sombreamento, em casa de vegetação com cobertura lateral de sombrite verde e cobertura superior de plástico transparente, procurando-se reproduzir a condição de clareira, com DFFA de ca. $50 \%$ em relação à condição de pleno sol; 4) $70 \%$ de sombreamento, em casa de vegetação com cobertura lateral e superior de sombrite verde escuro, reproduzindo a condição de dossel em fase de fechamento e com DFFA de ca. $30 \%$ em relação à condição de pleno sol e 5) $90 \%$ de sombreamento, em casa de vegetação com cobertura lateral e superior de uma camada dupla de sombrite verde escuro, reproduzindo a condição de dossel fechado com DFFA de $10 \%$.

Em intervalos de dois meses, para cada planta jovem, o diâmetro do coleto foi medido com um paquímetro digital com precisão de $0,01 \mathrm{~mm}$ e a altura foi medida com uma régua transparente com o ponto zero posicionado no nível do solo, indo até a gema apical. O número de folhas totalmente expandidas de cada planta também foi contado.

Após cada etapa de medição e contagem, efetuou-se a movimentação aleatória das plantas com o intuito de 
se obter homogeneização na ação de fatores não controlados. Em intervalos de quatro meses foram sorteados dez indivíduos de cada tratamento para a quantificação da massa seca. Cada planta foi destorroada, lavada com água corrente sobre mesa com cobertura telada e separada em folhas, caule e raízes. A seguir, foram colocadas em estufa a $70{ }^{\circ} \mathrm{C}$ até massa constante e avaliadas em balança de precisão de $0,01 \mathrm{~g}$. Antes da secagem, as folhas utilizadas na quantificação da massa seca tiveram a área foliar determinada por meio de um scanner (Area Meter, Mod. CI-202, CID Inc.).

A área foliar específica $(A F E)$ foi calculada dividindo-se a área foliar $\left(\mathrm{cm}^{2}\right)$ pela massa seca das folhas (g) de cada planta jovem. A razão da área foliar $(R A F)$ foi calculada dividindo-se a área total das folhas pela massa seca da planta (Green \& Newbery 2001). A taxa de crescimento relativo $(T C R)$ foi calculada seguindo-se as recomendações propostas por Hoffmann \& Poorter (2002) e para o cálculo da taxa de assimilação líquida $(T A L)$ utilizou-se a expressão proposta por Chiarello et al. (1991). As expressões matemáticas utilizadas para os cálculos foram:

$$
\begin{gathered}
\left.T C R=\overline{\left[\ln \left(\mathrm{b}_{2}\right)\right.}-\overline{\ln \left(\mathrm{b}_{1}\right)}\right] / \mathrm{t}_{2}-\mathrm{t}_{1} \\
T A L=2_{*}\left[\left(\mathrm{~b}_{2}-\mathrm{b}_{1}\right) /\left(\mathrm{t}_{2}-\mathrm{t}_{1}\right)\left(\mathrm{A}_{2}+\mathrm{A}_{1}\right)\right],
\end{gathered}
$$

onde: $\overline{\ln \left(\mathrm{b}_{1}\right)}$ e $\overline{\ln \left(\mathrm{b}_{2}\right)}$ são as médias (ln-transformadas) da massa seca (b) das plantas jovens no tempo inicial $\left(t_{1}\right)$ e no final $\left(t_{2}\right) ; b_{1}, b_{2}, A_{1}$ e $A_{2}$ são a massa seca da planta (b) e a área foliar total (A) no início $\left(t_{1}\right)$ e final $\left(t_{2}\right)$ do intervalo de tempo entre as duas medidas de biomassa.

A direção da distribuição da biomassa seca (DDBS) foi calculada de acordo com Claussen (1996), segundo a expressão:

$$
\left(M R_{2} / M_{S P A_{2}}-M S R_{1} / M S P A_{1}\right) /_{t_{i}-t_{2}}
$$

onde $\mathrm{MSR}_{2}$ : massa seca da raiz no tempo final, $M S P A_{2}$ : massa seca da parte aérea no tempo final, $M_{S R}$ : massa seca da raiz no tempo inicial, $M S P A_{l}$ : massa seca da parte aérea no tempo inicial, $t_{2}$ : tempo final e $t_{1}$ : tempo inicial. Valores positivos indicam que a distribuição da biomassa seca é típica de plantas que crescem em ambientes ensolarados, valores negativos indicam que a distribuição da biomassa é de plantas de sombra e DDBS igual a zero indica que a distribuição da biomassa não foi afetada no intervalo de tempo considerado.

Assimilação de $\mathrm{CO}_{2}$ e respiração foliar - As sementes de Brosimum rubescens utilizadas neste experimento foram coletadas na Fazenda Vera Cruz, semeadas no viveiro da FAL e mantidas sob condições similares às acima descritas. As mudas foram mantidas no viveiro durante 14 meses, nas condições de 0,30 e 90\% de sombrea- mento. As medições de assimilação de $\mathrm{CO}_{2}$ foram efetuadas em folhas adultas, sem imperfeições, posicionadas na porção apical do ramo, em cada uma das três diferentes condições de sombreamento. As folhas analisadas $(n=5)$ apresentaram tamanhos similares. As medidas foram determinadas com um sistema portátil para medir fotossíntese (Portable Photosynthesis System), modelo LCi da ADC Bio Scientific Ltd., em sistema aberto.

Cada folha, sem destacar da planta, foi encaixada dentro da câmara do aparelho e em seguida submetida a diferentes DFFA por um período de oito minutos em cada nível de luz, registrando-se os valores em intervalos de um minuto. Para este procedimento, utilizaram-se diferentes combinações de camadas de papel sulfite e vegetal e potências de luz (lâmpada de halogênio de 12 W, luz branca dicróica), simulando os seguintes níveis de DFFA: 0 (escuro), 5, 20, 50, 124, 170, 272, 468, 677, 947,1315 e $1746 \mu \mathrm{mol} \mathrm{m} \mathrm{m}^{-2} \mathrm{~s}^{-1}$. Assim, para cada folha procedeu-se o registro de 96 dados (taxa de assimilação de $\mathrm{CO}_{2}$ ), sendo oito para cada nível de irradiação. As médias aritméticas, calculadas para cada nível de DFFA (três últimas medidas a cada intensidade luminosa, após a estabilização da taxa fotossintética), foram utilizadas para a construção de curvas que relacionaram a taxa líquida de absorção ou liberação de $\mathrm{CO}_{2}$ e a DFFA.

Experimentos na floresta - $\mathrm{O}$ experimento em campo foi conduzido entre julho/2002 e julho/2004, na floresta monodominante de Brosimum rubescens da Fazenda Vera Cruz. Em intervalos de seis meses, efetuou-se a medição (altura total e diâmetro do coleto) e contagem das folhas em 30 plantas jovens de $B$. rubescens localizadas em uma clareira de $12,5 \times 7,5 \mathrm{~m}$ na floresta monodominante, classificada segundo critério adotado por Brokaw (1982) como de tamanho médio. As mesmas medidas foram efetuadas em 30 plantas jovens localizadas em uma área de $10 \times 10 \mathrm{~m}$ no sub-bosque da floresta, sob o dossel fechado, distante cerca de $50 \mathrm{~m}$ da clareira. Para caracterizar as condições luminosas de cada ambiente (clareira e sob o dossel fechado), no final da estação seca (setembro/2003) e no final da estação chuvosa (abril/2004), foi determinada a intensidade da irradiação solar com o uso de um sensor de quanta (LI190 SZ, LI-COR Inc. USA). Ao mesmo tempo também foram efetuadas leituras da DFFA em uma porção desmatada (lado de fora da floresta), a pleno sol. Em cada local de amostragem foram efetuadas quatro leituras com o sensor posicionado sobre uma plataforma nivelada, em intervalos regulares de 10 minutos, das 7 às 18 horas, conforme metodologia adotada por Felfili \& Abreu (1999). Foi traçado o curso diário da DFFA, medida em cada ambiente (clareira e sob o dossel) e a pleno sol, nas estações seca e chuvosa. Os valores médios de DFFA 
foram obtidos pela integração da curva diária de luz e os níveis percentuais de luz, nos dois ambientes, foram calculados em comparação proporcional com os níveis a pleno sol.

Plantas jovens, com cotilédones ligados ao coleto, foram selecionadas baseando-se em características morfológicas observadas desde 1996, em plantas que cresceram em viveiro e na floresta. Foram escolhidos indivíduos com alturas inferiores a $30 \mathrm{~cm}$, cujas sementes provavelmente foram produzidas em 2000.

Análises estatísticas - As respostas das plantas jovens aos diferentes tratamentos em viveiro foram avaliadas a partir de uma análise de variância, considerando-se a altura, diâmetro do coleto, número de folhas, massa seca (raiz, folhas, caule e total), relação raiz/parte aérea, área foliar e razão da área foliar. Para a comparação entre as médias dos tratamentos foi utilizado o teste de Tukey a 0,05 de significância.

A normalidade e a homocedasticidade dos dados foram analisadas pelos testes de Kolmogorov-Smirnov e Bartlett, respectivamente. Quando estas não foram comprovadas, os dados foram submetidos à transformação logarítmica para as variáveis contínuas e raiz quadrada para as variáveis discretas (Sokal \& Rolf 1981; Tabachnick \& Fidell 2001). Os testes estatísticos foram processados a partir do programa SAS 8.1 (SAS 1999-2000). Os resultados das comparações da área foliar específica (média, mediana e amplitude) entre os tratamentos foram apresentados em gráficos Box-Plot, utilizando-se o programa SYSTAT 7.0 (SPSS 1997).

Os valores máximos de assimilação de $\mathrm{CO}_{2}$ e de respiração no escuro para as plantas submetidas aos diferentes graus de sombreamento $(0,30$ e $90 \%)$ foram comparados por meio do teste de Kruskal-Wallis, utilizando-se o programa SYSTAT 7.0 (SPSS 1997). A eficiência fotossintética foi estimada como sendo a inclinação da reta, determinada a partir de regressão linear, utilizando-se os valores obtidos na parte inicial das curvas de resposta de assimilação de $\mathrm{CO}_{2}$ sob diferentes níveis de DFFA (DFFA até $170 \mu \mathrm{mol} \mathrm{m} \mathrm{m}^{-2} \mathrm{~s}^{-1}$ ).

Os dados medidos em campo (plantas jovens na clareira e sob o dossel) foram comparados a partir do teste de Mann-Whitney $(U)$ com o uso do programa SYSTAT 7.0 (SPSS 1997). As medições de luz foram comparadas entre a clareira e sob o dossel da floresta em cada estação (seca e chuva), por meio do teste de Mann-Whitney. Para as comparações pareadas entre seca e chuva, em cada porção de floresta, foi utilizado o teste de Wilcoxon. Para calcular a TIA (taxa relativa de incremento em altura) e a TID (taxa relativa de incremento em diâmetro) das plantas jovens que cresceram na clareira e sob o dossel, utilizou-se a expressão da $T C R$, substituindo-se os dados de biomassa pelas medidas de altura ou diâmetro no tempo inicial e final. Os valores da TIA e da TID na clareira e sob o dossel foram comparados a partir do teste de Mann-Whitney.

\section{Resultados}

Efeitos do sombreamento no crescimento das plantas em viveiro - Houve diferença significativa entre os tratamentos para as características de crescimento avaliadas (Tab. 2). A altura das plantas não diferiu significativamente até nove meses de idade e, a partir dos 11 meses, as maiores alturas foram registradas entre 30 e $70 \%$ de sombreamento. O diâmetro do coleto diferiu significativamente entre os tratamentos, para todas as idades avaliadas, sendo os maiores valores registrados para plantas crescendo até $50 \%$ de sombreamento, para a maioria das avaliações realizadas. O maior número de folhas em todas as idades amostradas foi registrado para as plantas mantidas a $50 \%$ de sombreamento, sem diferença significativa em relação aos valores registrados a $30 \%$ de sombreamento.

O desenvolvimento do sistema radicular e do caule ocorreu com maior sucesso em plantas mantidas desde pleno sol até $70 \%$ de sombreamento, exceto aos 17 meses de idade em que o maior sucesso ocorreu entre 50 e $70 \%$ de sombreamento. Esse padrão de crescimento se repetiu para a avaliação da biomassa seca total, apesar da biomassa de folhas ter apresentado comportamento diverso (Tab. 3). A biomassa particionada nas condições experimentais descritas obedeceu a ordem biomassa da raiz $>$ biomassa das folhas $>$ biomassa do caule. $\mathrm{O}$ maior sucesso das plantas também foi registrado entre zero e $70 \%$ de sombreamento, na avaliação da razão raiz/parte aérea e na razão da área foliar. O comportamento das plantas no que se refere à área foliar mostrou diferença significativa a partir de 17 meses, com a maior área registrada a 50 e $70 \%$ de sombreamento. Com 21 meses de idade as plantas mantidas a pleno sol tiveram redução significativa da área foliar em relação às mantidas a 50\% de sombreamento. A área foliar específica $(A F E)$ aumentou em função do aumento nos níveis de sombreamento, especialmente aos 17 e 21 meses de idade das plantas (Fig. 1).

Considerando-se todo o período amostrado (9 a 21 meses), a $T C R$ da raiz foi maior nos níveis intermediários de sombreamento (30 a 70\%) e a TCR da parte aérea foi maior, sem diferença significativa, de 30 a $90 \%$ de sombreamento (Tab. 4). Para a TAL, calculada no mesmo período, os valores foram baixos $\left(<0,0001380 \mathrm{~g} \mathrm{~cm}^{-2} \mathrm{~d}^{-1}\right)$ e não apresentaram diferença estatisticamente significativa entre os tratamentos (Tab. 4).

A direção da distribuição da biomassa seca (DDBS), considerando-se a relação raiz/parte aérea das plantas 
Tabela 2. Altura, diâmetro do coleto e número de folhas de plantas jovens de Brosimum rubescens Taub. submetidas a diferentes condições de sombreamento em viveiro. Médias seguidas de mesma letra na coluna, dentro de cada idade, não diferem entre si a 0,05 de probabilidade, pelo teste de Tukey.

\begin{tabular}{|c|c|c|c|c|}
\hline Idade (meses) & Tratamento & Altura (cm) & Diâmetro do coleto (mm) & $N^{o}$ folhas \\
\hline 7 & $0 \%$ sombra & $18,41 \mathrm{a}$ & $3,31 \mathrm{a}$ & $4 \mathrm{~b}$ \\
\hline \multirow[t]{4}{*}{ (abr./2002) } & $30 \%$ sombra & $18,45 \mathrm{a}$ & $3,05 \mathrm{ab}$ & $4 \mathrm{ab}$ \\
\hline & $50 \%$ sombra & $18,58 \mathrm{a}$ & $2,98 \mathrm{~b}$ & $5 a$ \\
\hline & $70 \%$ sombra & $18,29 \mathrm{a}$ & $2,96 b$ & $4 \mathrm{~b}$ \\
\hline & $90 \%$ sombra & $17,65 \mathrm{a}$ & $2,78 b$ & $4 \mathrm{~b}$ \\
\hline 9 & $0 \%$ sombra & $19,23 \mathrm{a}$ & $3,58 \mathrm{a}$ & $5 b c$ \\
\hline \multirow[t]{4}{*}{ (jun./2002) } & $30 \%$ sombra & $20,27 \mathrm{a}$ & $3,37 \mathrm{ab}$ & $6 a b$ \\
\hline & $50 \%$ sombra & $20,30 \mathrm{a}$ & $3,40 \mathrm{ab}$ & $6 \mathrm{a}$ \\
\hline & $70 \%$ sombra & $19,65 \mathrm{a}$ & $3,25 b c$ & $5 \mathrm{c}$ \\
\hline & $90 \%$ sombra & $18,57 \mathrm{a}$ & $3,02 \mathrm{c}$ & $5 \mathrm{c}$ \\
\hline 11 & $0 \%$ sombra & $19,33 b$ & $3,73 a$ & $6 \mathrm{bc}$ \\
\hline \multirow[t]{4}{*}{ (ago./2002) } & $30 \%$ sombra & $20,85 \mathrm{ab}$ & $3,69 \mathrm{ab}$ & $7 \mathrm{ab}$ \\
\hline & $50 \%$ sombra & $22,13 \mathrm{a}$ & $3,89 \mathrm{a}$ & $8 \mathrm{a}$ \\
\hline & $70 \%$ sombra & $20,53 \mathrm{ab}$ & $3,60 \mathrm{ab}$ & $6 \mathrm{bc}$ \\
\hline & $90 \%$ sombra & $19,55 \mathrm{~b}$ & $3,28 b$ & $5 c$ \\
\hline \multirow{5}{*}{$\begin{array}{c}13 \\
\text { (out./2002) }\end{array}$} & $0 \%$ sombra & $21,37 \mathrm{~b}$ & $4,00 \mathrm{~b}$ & $8 \mathrm{bc}$ \\
\hline & $30 \%$ sombra & $23,65 \mathrm{ab}$ & $4,11 \mathrm{ab}$ & $9 \mathrm{ab}$ \\
\hline & $50 \%$ sombra & $26,07 \mathrm{a}$ & $4,51 \mathrm{a}$ & $10 \mathrm{a}$ \\
\hline & $70 \%$ sombra & $22,75 b$ & $3,93 b c$ & $8 b c$ \\
\hline & $90 \%$ sombra & $21,37 b$ & $3,47 \mathrm{c}$ & $6 c$ \\
\hline \multirow{5}{*}{$\begin{array}{c}15 \\
(\operatorname{dez} . / 2002)\end{array}$} & $0 \%$ sombra & $23,33 b$ & $4,56 \mathrm{~b}$ & $10 \mathrm{~b}$ \\
\hline & $30 \%$ sombra & $27,11 b$ & $4,72 b$ & $13 a$ \\
\hline & $50 \%$ sombra & $31,87 \mathrm{a}$ & $5,41 \mathrm{a}$ & $15 \mathrm{a}$ \\
\hline & $70 \%$ sombra & $24,87 b$ & $4,34 \mathrm{bc}$ & $9 b$ \\
\hline & $90 \%$ sombra & $23,98 b$ & $3,80 \mathrm{c}$ & $8 \mathrm{~b}$ \\
\hline \multirow{5}{*}{$\begin{array}{c}17 \\
\text { (fev./2003) }\end{array}$} & $0 \%$ sombra & $25,28 \mathrm{c}$ & $5,03 b c$ & $13 \mathrm{bc}$ \\
\hline & $30 \%$ sombra & $29,93 b$ & $5,61 \mathrm{ab}$ & $15 \mathrm{ab}$ \\
\hline & $50 \%$ sombra & $35,62 \mathrm{a}$ & $6,29 \mathrm{a}$ & $18 \mathrm{a}$ \\
\hline & $70 \%$ sombra & $28,53 \mathrm{bc}$ & $4,77 \mathrm{c}$ & $11 \mathrm{~cd}$ \\
\hline & $90 \%$ sombra & $26,95 \mathrm{bc}$ & $4,04 d$ & $9 \mathrm{~d}$ \\
\hline \multirow{5}{*}{$\begin{array}{c}19 \\
\text { (abr./2003) }\end{array}$} & $0 \%$ sombra & $26,05 \mathrm{c}$ & $5,97 \mathrm{~b}$ & $15 \mathrm{ab}$ \\
\hline & $30 \%$ sombra & $34,33 \mathrm{ab}$ & $6,34 a b$ & $17 \mathrm{a}$ \\
\hline & $50 \%$ sombra & $39,20 \mathrm{a}$ & $7,07 \mathrm{a}$ & $20 \mathrm{a}$ \\
\hline & $70 \%$ sombra & $29,72 b c$ & $5,42 \mathrm{~b}$ & $12 \mathrm{~b}$ \\
\hline & $90 \%$ sombra & $29,53 \mathrm{bc}$ & $4,38 \mathrm{c}$ & $11 \mathrm{~b}$ \\
\hline \multirow{5}{*}{$\begin{array}{c}21 \\
\text { (jun./2003) }\end{array}$} & $0 \%$ sombra & $26,28 \mathrm{c}$ & $6,41 b$ & $15 \mathrm{bc}$ \\
\hline & $30 \%$ sombra & $35,20 \mathrm{ab}$ & $6,65 a b$ & $18 \mathrm{ab}$ \\
\hline & $50 \%$ sombra & $40,92 \mathrm{a}$ & $7,66 \mathrm{a}$ & $21 \mathrm{a}$ \\
\hline & $70 \%$ sombra & $31,00 \mathrm{bc}$ & $5,82 \mathrm{~b}$ & $12 \mathrm{bc}$ \\
\hline & $90 \%$ sombra & $31,66 b c$ & $4,70 \mathrm{c}$ & $12 \mathrm{c}$ \\
\hline
\end{tabular}

mantidas a pleno sol, apresentou valores de $-0,00105$ aos 13 meses, - 0,00021 aos 17 meses e 0,00019 aos 21 meses de idade das plantas, indicando habilidade de aclimatação com o aumento da idade da planta.

Entre 13 e 17 meses de idade algumas plantas jovens localizadas na casa de vegetação sob $30 \%$ de sombreamento foram atacadas por um inseto coccídeo (Homoptera, Diaspididae) que atingiu o caule e as folhas.
Tão logo foi constatado o ataque dos insetos, estes foram eliminados por controle manual e as plantas foram rigorosamente monitoradas no sentido de evitar re-infestação, mas seus efeitos alteraram a atividade metabólica das plantas. No período anterior ao ataque dos coccídeos, a biomassa foliar das plantas desse tratamento aumentou $116 \%$ entre as medições efetuadas aos nove e 13 meses. No período de infestação o aumento 
Tabela 3. Massa seca, relação raiz/parte aérea, área foliar e razão da área foliar de plantas jovens de Brosimum rubescens Taub., crescendo em viveiro, sob diferentes graus de sombreamento. Médias seguidas de mesma letra na coluna, dentro de cada idade, não diferem entre si a 0,05 de probabilidade, pelo teste de Tukey.

\begin{tabular}{|c|c|c|c|c|c|c|c|c|}
\hline \multirow[t]{2}{*}{ Idade (meses) } & \multirow[t]{2}{*}{ Tratamento } & \multicolumn{4}{|c|}{ Massa seca } & \multirow{2}{*}{$\begin{array}{l}\text { Relação raiz/ } \\
\text { parte aérea }\end{array}$} & \multirow{2}{*}{$\begin{array}{l}\text { Área foliar } \\
\left(\mathrm{cm}^{2}\right)\end{array}$} & \multirow{2}{*}{$\begin{array}{l}\text { Razão da } \\
\text { área foliar } \\
\left(\mathrm{cm}^{2} \mathrm{~g}^{-1}\right)\end{array}$} \\
\hline & & Raiz & Folhas & Caule & Total & & & \\
\hline \multirow{5}{*}{$\begin{array}{c}9 \\
\text { (jun./2002) }\end{array}$} & $0 \%$ sombra & $0,82 \mathrm{a}$ & $0,47 \mathrm{ab}$ & $0,43 a$ & $1,72 \mathrm{a}$ & $0,90 \mathrm{a}$ & $51,97 \mathrm{a}$ & $30,26 a$ \\
\hline & $30 \%$ sombra & $0,80 \mathrm{a}$ & $0,56 \mathrm{a}$ & $0,47 \mathrm{a}$ & $1,84 \mathrm{a}$ & $0,73 \mathrm{ab}$ & $68,18 \mathrm{a}$ & $37,88 \mathrm{bc}$ \\
\hline & $50 \%$ sombra & $0,68 \mathrm{ab}$ & $0,52 \mathrm{ab}$ & $0,39 \mathrm{ab}$ & $1,71 \mathrm{ab}$ & $0,72 \mathrm{ab}$ & $59,76 a$ & $39,39 b c$ \\
\hline & $70 \%$ sombra & $0,70 \mathrm{a}$ & $0,44 \mathrm{ab}$ & $0,38 \mathrm{a}$ & $1,52 \mathrm{ab}$ & $0,85 \mathrm{ab}$ & $51,70 \mathrm{a}$ & $35,02 \mathrm{~b}$ \\
\hline & $90 \%$ sombra & $0,33 b$ & $0,26 \mathrm{~b}$ & $0,21 b$ & $0,80 \mathrm{~b}$ & $0,69 b$ & $36,92 \mathrm{a}$ & $46,79 \mathrm{c}$ \\
\hline \multirow{5}{*}{$\begin{array}{c}13 \\
\text { (out./2002) }\end{array}$} & $0 \%$ sombra & $0,86 \mathrm{ab}$ & $0,58 b$ & $0,53 \mathrm{ab}$ & $1,97 \mathrm{ab}$ & $0,77 \mathrm{a}$ & $78,29 \mathrm{a}$ & $42,35 \mathrm{a}$ \\
\hline & $30 \%$ sombra & $1,54 \mathrm{a}$ & $1,21 \mathrm{a}$ & $0,88 \mathrm{a}$ & $3,64 \mathrm{ab}$ & $0,74 a$ & $144,27 \mathrm{a}$ & $38,75 a$ \\
\hline & $50 \%$ sombra & $1,38 \mathrm{a}$ & $1,01 \mathrm{a}$ & $0,72 \mathrm{ab}$ & $3,11 \mathrm{a}$ & $0,78 \mathrm{a}$ & $119,40 \mathrm{a}$ & $38,70 \mathrm{a}$ \\
\hline & $70 \%$ sombra & $1,26 a b$ & $0,98 \mathrm{a}$ & $0,74 \mathrm{ab}$ & $2,98 \mathrm{ab}$ & $0,74 \mathrm{a}$ & $126,07 \mathrm{a}$ & $42,05 \mathrm{a}$ \\
\hline & $90 \%$ sombra & $0,71 b$ & $0,64 a b$ & $0,44 b$ & $1,80 \mathrm{~b}$ & $0,64 \mathrm{a}$ & $94,37 \mathrm{a}$ & $53,73 b$ \\
\hline \multirow{5}{*}{$\begin{array}{c}17 \\
\text { (fev./2003) }\end{array}$} & $0 \%$ sombra & $1,59 b c$ & $0,97 b$ & $0,90 \mathrm{~b}$ & $3,47 b c$ & $0,85 \mathrm{a}$ & $100,04 b$ & $28,88 \mathrm{a}$ \\
\hline & $30 \%$ sombra & $1,81 b c$ & $1,38 b$ & $1,02 \mathrm{~b}$ & $4,21 b c$ & $0,73 a$ & $145,16 b$ & $35,22 \mathrm{ab}$ \\
\hline & $50 \%$ sombra & $3,40 \mathrm{a}$ & $2,37 \mathrm{a}$ & $1,85 \mathrm{a}$ & $7,61 \mathrm{a}$ & $0,78 \mathrm{a}$ & $251,19 \mathrm{a}$ & $36,45 \mathrm{ab}$ \\
\hline & $70 \%$ sombra & $2,25 \mathrm{ab}$ & $1,47 \mathrm{ab}$ & $1,08 \mathrm{ab}$ & 4,80ab & $0,84 \mathrm{a}$ & $169,87 \mathrm{ab}$ & $37,49 b$ \\
\hline & $90 \%$ sombra & $0,88 \mathrm{c}$ & $0,95 \mathrm{~b}$ & $0,59 \mathrm{~b}$ & $2,43 c$ & $0,57 b$ & $152,93 b$ & $62,61 \mathrm{c}$ \\
\hline \multirow{5}{*}{$\begin{array}{c}21 \\
\text { (jun./2003) }\end{array}$} & $0 \%$ sombra & $3,00 \mathrm{ab}$ & $1,33 b$ & $1,65 \mathrm{ab}$ & $5,98 \mathrm{ab}$ & $0,97 \mathrm{a}$ & $115,14 b$ & $19,46 \mathrm{a}$ \\
\hline & $30 \%$ sombra & $4,04 \mathrm{a}$ & $2,42 \mathrm{ab}$ & $2,19 a$ & $8,66 \mathrm{a}$ & $0,90 \mathrm{a}$ & $223,93 \mathrm{ab}$ & $25,40 \mathrm{ab}$ \\
\hline & $50 \%$ sombra & $4,31 \mathrm{a}$ & $2,63 \mathrm{a}$ & $2,52 \mathrm{a}$ & $9,46 a$ & $0,86 a$ & $257,84 \mathrm{a}$ & $27,36 \mathrm{~b}$ \\
\hline & $70 \%$ sombra & $4,06 \mathrm{a}$ & $2,10 \mathrm{ab}$ & $1,88 \mathrm{ab}$ & $8,04 \mathrm{ab}$ & $0,97 \mathrm{a}$ & $226,63 \mathrm{ab}$ & $29,99 b$ \\
\hline & $90 \%$ sombra & $1,53 \mathrm{~b}$ & $1,34 \mathrm{~b}$ & $1,01 \mathrm{~b}$ & $3,88 \mathrm{~b}$ & $0,66 \mathrm{~b}$ & $181,99 \mathrm{ab}$ & $47,67 \mathrm{c}$ \\
\hline
\end{tabular}

da biomassa foliar foi de apenas $14 \%$ e após a eliminação dos insetos (17 e 21 meses) o aumento da biomassa foliar voltou a ser elevado, alcançando $75 \%$ (Tab. 3). Entre 17 e 21 meses, o único caso onde as plantas jovens cresceram mais do que nas idades anteriores foi para o tratamento sob $30 \%$, provavelmente em resposta à eliminação dos coccídeos.

A taxa fotossintética das plantas, avaliada pela assimilação de $\mathrm{CO}_{2}$, aumentou com o aumento da DFFA até um determinado nível luminoso, que variou dependendo da condição de sombreamento (Fig. 2). Sob $90 \%$ de sombreamento a assimilação de $\mathrm{CO}_{2}$ das plantas apresentou saturação à luz entre $200 \mathrm{e} 400 \mu \mathrm{mol} \mathrm{m}^{-2} \mathrm{~s}^{-1} \mathrm{e}$ sob 30\% de sombreamento a saturação ocorreu em torno de $600 \mu \mathrm{mol} \mathrm{m}^{-2} \mathrm{~s}^{-1}$. As plantas não sombreadas saturaram por volta de $900 \mu \mathrm{mol} \mathrm{m} \mathrm{m}^{-2} \mathrm{~s}^{-1}$. Os menores valores de taxa fotossintética máxima $\left(3,46 \mu \mathrm{mol} \mathrm{m} \mathrm{m}^{-2} \mathrm{~s}^{-1}\right)$ foram obtidos no tratamento sob $90 \%$ de sombreamento e a pleno sol $\left(3,76 \mu \mathrm{mol} \mathrm{m}^{-2} \mathrm{~s}^{-1}\right)$ e os maiores foram registrados sob $30 \%$ de sombreamento $\left(7,89 \mu \mathrm{mol} \mathrm{m}^{-2} \mathrm{~s}^{-1}\right)$.

Observando-se na Fig. 2 as porções correspondentes até $170 \mu \mathrm{mol} \mathrm{m} \mathrm{m}^{-2} \mathrm{~s}^{-1}$, é possível verificar que ocorre diferença na eficiência fotossintética das folhas, visto que a inclinação das retas foi maior para as que cresceram sob 30 e $90 \%$ de sombreamento (0\% de sombreamento:
$\mathrm{Y}=0,0066 \mathrm{x}-0,3647, r^{2}=0,65, P<0,05 ; 30 \%$ de sombreamento: $\mathrm{Y}=0,0308 \mathrm{x}-0,5001, r^{2}=0,98, P<0,05$ e $90 \%$ de sombreamento: $\mathrm{Y}=0,0135 \mathrm{x}-0,1648, r^{2}=0,96$, $P<0,05)$. Comparando-se os valores de respiração, determinados no escuro, observou-se que houve diferença estatisticamente significativa entre as folhas que cresceram nos três diferentes tratamentos (KruskalWallis $=12,02, P=0,002)$, sendo que a taxa de respiração das folhas que cresceram a pleno sol $\left(-1,34 \mu \mathrm{mol} \mathrm{m}^{-2} \mathrm{~s}^{-1}\right)$ foi maior do que as que cresceram sob $30 \%(-0,63)$ e $90 \%(-0,11)$ de sombreamento e essas últimas foram similares entre si.

Experimentos na floresta - Comparando-se as variáveis medidas em plantas jovens localizadas sob o dossel e em clareira, verificou-se que não houve diferença significativa ( $P>0,05$, teste de Mann-Whitney) entre o número de folhas e entre os diâmetros determinados em intervalos de seis meses, por um período de dois anos. As alturas, determinadas em julho/2002, também não diferiram entre as plantas que cresceram sob o dossel e aquelas da clareira. Entretanto, em todas as medições posteriores as alturas diferiram significativamente, sendo sempre maiores na clareira (janeiro/2003: $U=603,5 \mathrm{e}$ $P=0,0043$; julho/2003: $U=571,5$ e $P=0,0029$; 
9 meses

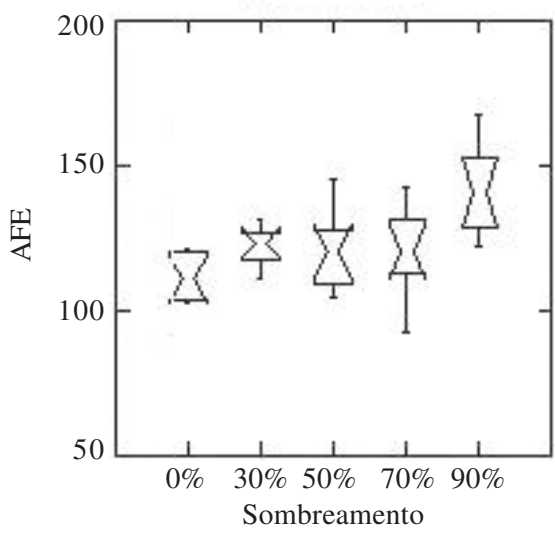

17 meses

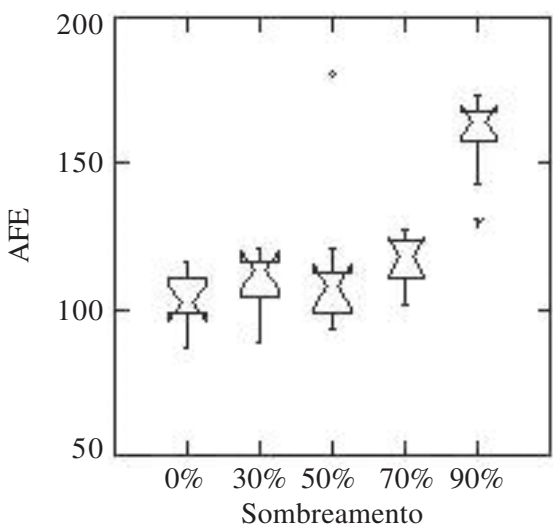

13 meses

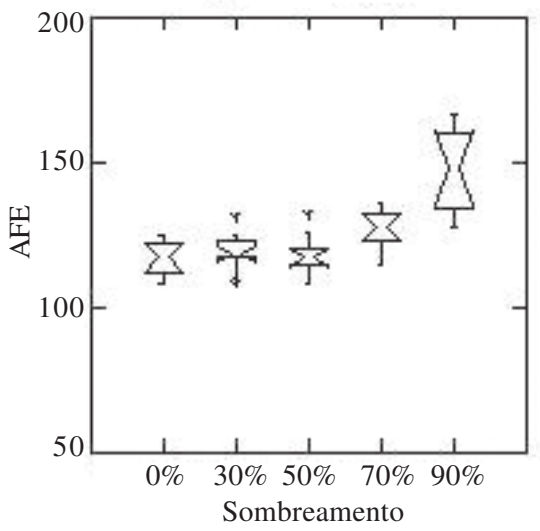

21 meses

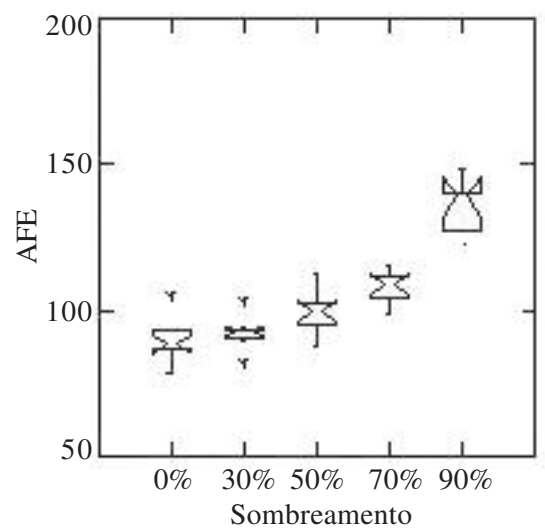

Figura 1. Box-Plot representando as médias, medianas e a amplitude da área foliar específica $\left(A F E, \mathrm{~cm}^{2} \mathrm{~g}^{-1}\right)$ em diferentes idades de plantas jovens de Brosimum rubescens Taub. submetidas a diferentes níveis de sombreamento em viveiro.

Tabela 4. Taxa de crescimento relativo $\left(T C R, \mathrm{~g} \mathrm{~g}^{-1} \mathrm{~d}^{-1}\right)$ de raízes e da parte aérea (folhas e caule) e taxa de assimilação líquida (TAL, $\left.\mathrm{g} \mathrm{cm}^{-2} \mathrm{~d}^{-1}\right)$ de plantas jovens de Brosimum rubescens Taub., submetidas a diferentes graus de sombreamento em viveiro, entre 9 e 21 meses de idade. Médias seguidas de mesma letra não diferem entre si a 0,05 de probabilidade, pelo teste de Tukey.

\begin{tabular}{lccc}
\hline Tratamento & \multicolumn{2}{c}{$T C R$} & \multirow{2}{*}{ TAL } \\
\cline { 2 - 3 } & Raiz & Parte aérea & \\
\hline $0 \%$ sombra & $0,0032 \mathrm{~b}$ & $0,0030 \mathrm{~b}$ & $0,0001356 \mathrm{a}$ \\
$30 \%$ sombra & $0,0048 \mathrm{ac}$ & $0,0042 \mathrm{a}$ & $0,0001380 \mathrm{a}$ \\
$50 \%$ sombra & $0,0054 \mathrm{a}$ & $0,0049 \mathrm{a}$ & $0,0001359 \mathrm{a}$ \\
$70 \%$ sombra & $0,0046 \mathrm{ac}$ & $0,0042 \mathrm{a}$ & $0,0001248 \mathrm{a}$ \\
$90 \%$ sombra & $0,0040 \mathrm{bc}$ & $0,0042 \mathrm{a}$ & $0,0000175 \mathrm{a}$ \\
\hline
\end{tabular}

janeiro/2004: $U=580,5$ e $P=0,0017$; julho/2004: $U=587,0$ e $P=0,001)$. Na clareira, foi registrada a morte de dois indivíduos e sob o dossel fechado o evento não foi registrado.

Os valores da taxa de incremento em altura (TIA) das plantas jovens localizadas sob o dossel $\left(8,3.10^{-6} \mathrm{a}\right.$ $\left.2,1 \cdot 10^{-5}\right)$ e na clareira $\left(0,00018\right.$ a $\left.0,00031 \mathrm{~cm} \mathrm{~cm}^{-1} \mathrm{~d}^{-1}\right)$ diferiram entre si nos três períodos avaliados (janeiro/2003 a julho/2003: $U=638,0$ e $P=0,002$; julho/2003 a janeiro/2004: $U=527,5$ e $P=0,024$ e janeiro/2004 a julho/2004: $U=530,1$ e $P=0,022$ ). Comparando-se as taxas de incremento em diâmetro (TID) entre julho/2003 e janeiro/2004 e entre janeiro e julho/2004, não foi registrada diferença estatisticamente significativa $(U=460,5, P=0,199$ e $U=346, P=0,463$, respectivamente).

O curso diário da DFFA variou entre a clareira $\left(\mathrm{seca}=9,5\right.$ a $1.874,7$ e chuva $=5,2$ a $\left.1.213,1 \mu \mathrm{mol} \mathrm{m}^{-2} \mathrm{~s}^{-1}\right)$ e sob o dossel (seca $=1,89$ a 508,5 e chuva $=0,5$ a $200,8 \mu \mathrm{mol} \mathrm{m} \mathrm{m}^{-2} \mathrm{~s}^{-1}$ ). Nas comparações pareadas entre seca e chuva, no mesmo ambiente, foi registrada diferença significativa entre os níveis de luz para ambos (sob o dossel: $Z=-4,3853, P<0,001$ e na clareira: $Z=-4,0433, P<0,001)$. Também foi registrada diferença significativa para as medições, comparando-se a clareira e sob o dossel na estação chuvosa $(U=191$ e $P<0,001)$ e na estação seca $(U=278$ e $P=0,0002)$. O percentual 


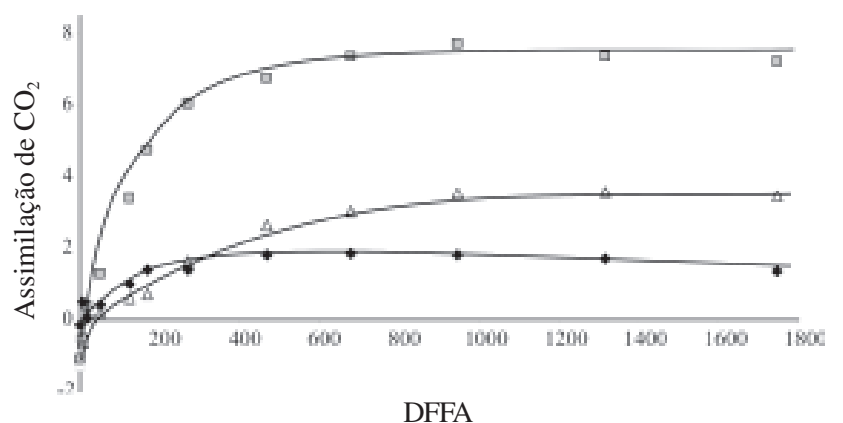

Figura 2. Assimilação de $\mathrm{CO}_{2}\left(\mu \mathrm{mol} \mathrm{m} \mathrm{m}^{-2} \mathrm{~s}^{-1}\right)$ de folhas de plantas jovens de Brosimum rubescens Taub. crescendo sob diferentes níveis de irradiação luminosa na faixa fotossinteticamente ativa (DFFA, $\mu \mathrm{mol} \mathrm{m} \mathrm{m}^{-2} \mathrm{~s}^{-1}$ ) sob $0 \%, 30 \%$ e $90 \%$ de sombreamento, em viveiro. Valores correspondem à média de cinco folhas por tratamento. $(\triangle=0 \%$ Sombra; $=30 \%$ Sombra; $\bullet=90 \%$ Sombra $)$.

total diário de luz sob o dossel foi de aproximadamente $2 \%$ na estação chuvosa e 3,5\% na seca e na clareira foi de $9 \%$ e $20 \%$, respectivamente.

\section{Discussão}

As plantas jovens de Brosimum rubescens, avaliadas em viveiro e em condições naturais, crescem melhor entre 30 e $70 \%$ de sombreamento e são persistentes, tanto sob condições de elevado sombreamento como a pleno sol, com crescimento lento e reduzida taxa fotossintética nessas condições extremas de luz. O crescimento e a produção de biomassa das plantas jovens de $B$. rubescens em viveiro, aos 21 meses, em todos os tratamentos, foram similares aos registrados para algumas espécies arbóreas de floresta de galeria com idades entre 17 e 24 meses, onde Ormosia stipularis Ducke (Mazzei et al. 1997), Cryptocaria aschersoniana Mez. (Rezende et al. 1998) e Sclerolobium paniculatum Vogel (Felfili et al. 1999) também apresentaram os melhores resultados com 50\% de sombreamento. Os resultados obtidos por Poorter (1999) para 15 espécies da Amazônia, de diferentes grupos sucessionais, também demonstraram que, em geral, a maior biomassa é alcançada nas condições intermediárias de luz.

No presente estudo, os maiores valores da relação raiz/parte aérea foram registrados dentro de um amplo intervalo de sombreamento (0 a 70\%) e, de forma geral, os menores valores foram observados sob $90 \%$ de sombreamento. $\mathrm{O}$ maior investimento em biomassa radicular sob condições de menor sombreamento evidencia que o desenvolvimento das raízes é imprescindível para que os indivíduos da espécie consigam sobreviver em condições naturais de elevada luminosidade (grandes clareiras) e com déficit hídrico sazonal. Para plântulas de oito espécies de árvores típicas de floresta de galeria revisadas por Felfili et al. (2001), maior relação raiz/parte aérea foi encontrada nas condições de menor sombreamento (sombra $=0,4$ a 1,4 e sol $=1,3$ a 3 ) e para uma espécie pioneira estudada por Alvarenga et al. (2003), plântulas submetidas a um menor sombreamento também deslocaram maior massa seca nas raízes em relação às que cresceram sob maior sombreamento. Duz et al. (2004) observaram que a tendência da razão raiz/parte aérea em plântulas de três espécies arbóreas da floresta atlântica foi aumentar com o aumento dos níveis de luz $(0,1$ até cerca de 0,6$)$.

Desta maneira, espécies adaptadas a estresse hídrico mais acentuado podem apresentar valores elevados da relação raiz/parte aérea sob condições de elevada irradiação solar. Ramos et al. (2004) observaram que a relação raiz/parte aérea de mudas de Amburana cearensis (Allemão) A.C. Sm. crescendo a pleno sol era de 4,11. Hoffmann et al. (2004), comparando plântulas de espécies congenéricas de ambientes savânicos e florestais, verificaram que aquelas típicas de cerrado apresentavam maior investimento na biomassa radicular, garantindo seu estabelecimento e sobrevivência em áreas mais abertas. De acordo com Popma \& Bongers (1988), essa característica possibilita maior absorção de água para suprir a demanda transpiratória, permitindo às plantas maior habilidade para suportar taxas fotossintéticas elevadas, já que diminuiria a necessidade de controlar a abertura estomática para restringir a transpiração. No caso de Brosimum rubescens, é possível supor que o maior investimento no crescimento radicular em condições de elevada luminosidade poderia conferir vantagens competitivas a esta espécie, principalmente no período da seca, contribuindo para a manutenção de sua monodominância.

A direção da distribuição da biomassa seca (DDBS) registrada para as plantas jovens de Brosimum rubescens que cresceram a pleno sol indicou que estas apresentam habilidade de aclimatação às variações nos níveis de luz. Claussen (1996) observou que a mudança da DDBS de valores negativos para valores positivos, tal como observado para $B$. rubescens, seria um indicativo de que a adaptação morfológica da planta seguiria um padrão exibido por plantas que crescem em ambientes de sol. Uma ampla plasticidade ou aclimatação a diferentes níveis de luz também foi registrada por Felfili et al. (2001) para espécies de floresta de galeria e por Ramos et al. (2004) e Lima Júnior et al. (2006), para espécies de floresta estacional. Brosimum alicastrum Sw., uma espécie arbórea de floresta tropical do México, apresentou elevada aclimatação ao aumento dos níveis de irradiação solar (Strauss-Debenedetti \& Bazzaz 1991).

Apesar de apresentar plasticidade em relação aos níveis de luminosidade, as plantas jovens de Brosimum rubescens desenvolveram-se melhor sob níveis 
intermediários de luz em viveiro. Augspurger (1984) e Veenendaal et al. (1996) estudaram plântulas de diversas espécies de árvores de florestas tropicais e verificaram que a maioria alcançou taxas de crescimento mais elevadas nas condições intermediárias de luz. No caso de B. rubescens, foi registrado crescimento mesmo sob níveis extremos de sombreamento $(90 \%)$. Entretanto, em uma condição similar à clareira $(50 \%$ de sombreamento), o crescimento foi significativamente mais acentuado, podendo conferir à espécie uma vantagem competitiva na ocupação de ambientes mais iluminados na floresta. Convém salientar que podem ocorrer respostas distintas em cada ambiente e, neste caso, as taxas de crescimento podem variar entre as condições naturais e de viveiro.

Neste caso, é de se esperar que plantas jovens de Brosimum rubescens cresçam muito lentamente sob o dossel, sendo que durante e após a formação de uma clareira este crescimento se tornaria significativamente maior, podendo classificar suas plantas como persistentes, tal como verificado para Copaifera langsdorffii Desf. em floresta de galeria (Felfili 1997). Brown \& Whitmore (1992) observaram que a habilidade de persistir por longos períodos sob o dossel fechado e apresentar crescimento lento podem dar às plantas jovens vantagens quando uma clareira se abre. No caso da floresta analisada no presente estudo, a ocorrência de um denso banco de plântulas persistente no sub-bosque pode resultar na manutenção da monodominância de $B$. rubescens em função do seu potencial de ocupar o sub-bosque e de responder rapidamente à abertura de clareiras. Desta forma, fatores bióticos relativos à herbivoria, alelopatia e associação com micorrizas parecem não estar relacionados com a monodominância de B. rubescens (B.S. Marimon, dados não publicados).

Em condições naturais na floresta monodominante de Brosimum rubescens, as plantas jovens localizadas em clareira apresentaram maior crescimento em altura do que aquelas localizadas sob o dossel fechado. Poorter \& Hayashida-Oliver (2000) observaram que as plântulas de Brosimum lactescens (S. Moore) C.C. Berg., espécie arbórea comum na Amazônia boliviana, também apresentaram maior crescimento em altura em clareiras. Os autores observaram ainda que o maior crescimento em altura nas clareiras, durante a estação chuvosa, conferiu a essas plantas vantagem decisiva sobre aquelas que cresceram no sub-bosque durante a estação seca. No caso de $B$. rubescens, para as medições efetuadas na floresta, parece ocorrer um efeito positivo do crescimento no período das chuvas. Entretanto, esse padrão precisa ser melhor investigado.

Em geral, à medida que aumentou o nível de exposição à irradiação solar, as plantas jovens de
Brosimum rubescens apresentaram folhas mais espessas (menor $A F E$ ), com maior eficiência fotossintética (menor $R A F$ ) e maior alocação de biomassa para as raízes (maior relação raiz/parte aérea). Isso mostra que as plantas apresentam plasticidade fenotípica ao fator luz porque são capazes de alterar seu comportamento à medida que a irradiação solar aumenta ou diminui. Chen \& Klinka (1998) e Bloor \& Grubb (2004) observaram que espécies tolerantes à sombra apresentam $A F E$ com maior plasticidade em resposta à disponibilidade de luz, ao passo que as espécies intolerantes apresentam menor plasticidade. Assim, B. rubescens pode ser considerada uma espécie tolerante ao sombreamento e também à alta irradiância, visto que a maior alocação de biomassa para as raízes, quando exposta a níveis de menor sombreamento, confere à espécie tolerância ao sol e isto pode ser um ponto-chave para garantir a sua monodominância na floresta, ou seja, sob condições extremas de sombreamento ela se comporta como tolerante à sombra e sob condições de clareira ela se comporta como tolerante ao sol.

Em condições de maior sombreamento, maiores valores de $A F E$ contribuem para aumentar a taxa de crescimento das plântulas pois, segundo alguns autores (Chen \& Klinka 1998; Poorter 1999; Fownes \& Harrington 2004), esta característica confere maior interceptação de luz e ganho de carbono por unidade de massa investida nas folhas. Por outro lado, em ambientes com muita luz, valores menores de $A F E$ seriam benéficos, pois menor biomassa por unidade de área estaria diretamente exposta, reduzindo a perda de água (Popma \& Bongers 1988; 1991; Claussen 1996; Duz et al. 2004). Neste caso, o espessamento da folha (menor $A F E$ ), quando exposta à alta intensidade luminosa, geralmente resulta em aumento das camadas de parênquima fotossinteticamente ativo e isto poderia aumentar a capacidade fotossintética da folha (Poorter 1999). Entretanto, Reich et al. (1998) analisaram 257 espécies de florestas temperadas, tropicais e desertos e observaram que as mudanças que ocorrem em folhas com menor $A F E$, ao contrário do que seria esperado, poderiam representar uma desvantagem devido ao maior sombreamento interno da folha, em função do empilhamento dos cloroplastos causando, portanto, limitação na difusão de gases.

Se for considerado que em florestas tropicais, em geral, somente 1 a $2 \%$ da irradiação solar alcança o solo da floresta, tal como foi registrado no sub-bosque da floresta estudada, é de se esperar que as plantas jovens neste ambiente cresçam muito lentamente. Clark \& Clark (1992) observaram que em um período de quatro anos, arvoretas de diversas espécies localizadas no sub-bosque não apresentaram crescimento. No caso de Brosimum 
rubescens, os menores valores de acúmulo de biomassa em viveiro foram registrados para as plantas jovens que cresceram a $90 \%$ de sombreamento e na floresta, as plantas localizadas sob o dossel também apresentaram menor crescimento em altura do que aquelas crescendo em clareira.

A TCR registrada para Brosimum rubescens foi bastante reduzida e os valores registrados nos tratamentos sob sombreamento foram similares aos menores registrados por Hoffmann \& Franco (2003) para esta mesma espécie, sob condições de viveiro, entre 0 e $26 \%$ de sombreamento. Apesar de ser esperado maior valor de TCR (especialmente em espécies pioneiras) com o aumento da irradiação (Sipe \& Bazzaz 1995; Poorter 1999), foram os níveis intermediários de luz que permitiram melhor crescimento de B. rubescens, provavelmente porque as plantas jovens que cresceram a pleno sol, mesmo tendo sido irrigadas duas vezes ao dia, sofreram mais com o estresse hídrico ou com as elevadas temperaturas do solo. Esse tipo de comportamento também foi registrado por Poorter (1999) para 15 espécies arbóreas (pioneiras, intermediárias e tolerantes à sombra) de floresta tropical. Por outro lado, as plantas jovens de $B$. rubescens, em condições de viveiro, também apresentaram crescimento sob elevado sombreamento, reforçando a plasticidade da espécie às diferentes condições de luminosidade. Neste caso, de acordo com as guildas de regeneração propostas por Swaine \& Whitmore (1988), B. rubescens pode ser classificada como espécie clímax exigente de luz, cujas sementes germinam e as plantas jovens crescem em condições de sombreamento, embora os jovens imaturos necessitem de luz para crescer e atingir o dossel.

Considerando-se que as plantas jovens de Brosimum rubescens localizadas na clareira da floresta apresentaram melhor crescimento em altura do que aquelas avaliadas sob o dossel, é possível sugerir que após a abertura de uma clareira natural, essas plantas poderiam aumentar a TIA, aproveitando esta nova condição de luminosidade. Bazzaz \& Pickett (1980) observaram que plântulas crescendo no sub-bosque de uma floresta apresentam metabolismo "lutador", adaptado ao fornecimento contínuo de baixos níveis de recursos, ou metabolismo "jogador", que aparece em espécies dependentes de clareiras e com taxas metabólicas mais flexíveis, capazes de responder aos pulsos de recursos. Neste caso, sugere-se que as plantas jovens de B. rubescens apresentam metabolismo do tipo "lutador-jogador", com indivíduos persistentes crescendo lentamente sob o dossel, mas que apresentam maior crescimento quando submetidos a condições intermediárias de irradiação (50\% de sombreamento), semelhante ao que se observa em clareiras de tamanho médio, como aquelas avaliadas por Mesquita (2000) na Amazônia brasileira.

Analisando os resultados da taxa fotossintética máxima $\left(\mathrm{A}_{\mathrm{max}}\right)$ de Brosimum rubescens nos diferentes tratamentos de luminosidade, em viveiro, observa-se que essa espécie apresentou níveis similares a outras espécies tropicais, principalmente aquelas que ocorrem com mais frequiência em áreas mais sombreadas (Bazzaz 1991). Oberbauer \& Strain (1984), estudando espécies da floresta tropical da Costa Rica, observaram que plantas de ambientes sombreados apresentam taxa fotossintética média de $6,8 \mu \mathrm{mol} \mathrm{m} \mathrm{m}^{-2} \mathrm{~s}^{-1}$, as que ocorrem em clareiras abertas no dossel apresentam taxa média de $11,3 \mu \mathrm{mol} \mathrm{m}^{-2} \mathrm{~s}^{-1} \mathrm{e}$ aquelas que ocorrem em grandes clareiras, taxa de $27,7 \mu \mathrm{mol} \mathrm{m}^{-2} \mathrm{~s}^{-1}$. B. rubescens apresentou os maiores valores de $A_{\text {máx }}\left(7,89 \mu \mathrm{mol} \mathrm{m}^{-2} \mathrm{~s}^{-1}\right)$ sob a condição de $30 \%$ de sombreamento, reforçando que esta seria mais adequada para o crescimento das plantas jovens, quando comparada com 0 e $90 \%$ de sombreamento. Os valores de $A_{\text {máx }}$ observados por StraussDebenedetti \& Bazzaz (1991) para B. alicastrum, uma espécie sucessional secundária emergente, variaram de 4,1 a $5,9 \mu \mathrm{mol} \mathrm{m}^{-2} \mathrm{~s}^{-1}$ sob três diferentes níveis de luminosidade $(8,37$ e $100 \%$ de irradiação). Entretanto, é necessário ser cauteloso antes de extrapolar para as condições naturais os resultados obtidos sob condições de viveiro, principalmente quando ainda se conhece pouco sobre a biologia de uma espécie, como é o caso de $B$. rubescens.

As folhas das plantas jovens de Brosimum rubescens que cresceram sob $90 \%$ de sombreamento apresentaram saturação à luz inferior àquela observada para as que cresceram a pleno sol. Este padrão está de acordo com o que foi observado por Oberbauer \& Strain (1984), Bazzaz (1991) e Press et al. (1996), segundo os quais a saturação à luz para as plantas de clareiras ocorre em níveis de DFFA maiores que $1.000 \mu \mathrm{mol} \mathrm{m}^{-2} \mathrm{~s}^{-1}$ e para as plantas de sub-bosque a saturação ocorre em níveis de DFFA muito menores. Santos \& Buckeridge (2004) verificaram que plântulas de Hymenaea courbaril L., uma espécie arbórea da América tropical e tolerante à sombra, apresenta ponto de saturação à luz de $200 \mu \mathrm{mol} \mathrm{m}^{-2} \mathrm{~s}^{-1}$. Com base nesses valores, parece que $B$. rubescens tolera níveis relativamente altos de sombreamento ou de irradiação solar, mas tem melhor desempenho fotossintético quando exposta a condições intermediárias de luz, que pode corresponder à fase de fechamento do dossel ou a clareiras de tamanho médio, segundo Brokaw (1982). Considerando-se que os melhores desempenhos registrados para as plantas jovens de $B$. rubescens foram sob níveis intermediários de sombreamento (viveiro) ou em clareira (floresta), sugere-se que o ponto de saturação à luz e $\mathrm{A}_{\text {máx }}$ maiores, registrados sob $30 \%$ de sombreamento, poderiam conferir vantagens competitivas a essas plantas, visto que após a formação de uma 
clareira elas competiriam com espécies sucessionais primárias, que naturalmente apresentam elevadas taxas fotossintéticas, elevado ponto de saturação à luz e rápido crescimento, como foi observado por Bazzaz (1991), Bazzaz \& Pickett (1980) e Ellsworth \& Reich (1996).

Em síntese, pode-se concluir que os melhores resultados para as variáveis avaliadas no presente estudo para as plantas jovens de Brosimum rubescens foram registrados nas condições intermediárias de sombreamento em viveiro e na condição de clareira em floresta. As plantas também apresentaram certa plasticidade com relação às diferentes condições de luminosidade. Porém, os resultados registrados nas condições extremas, de 0 e $90 \%$ de sombreamento, podem indicar que uma situação de excesso de luminosidade poderia comprometer o crescimento e uma situação de excesso de sombreamento poderia retardar o crescimento (plântulas persistentes) até o aparecimento de uma condição ambiental favorável (clareira). É possível supor que, no passado, dentre outros fatores, condições de maior luminosidade no sub-bosque permitiram que esta espécie se tornasse dominante e atualmente, apesar do sombreamento na floresta, a plasticidade característica da espécie permite que as plantas jovens persistam com baixas taxas de crescimento até que ocorra a abertura de uma clareira, mantendo-se assim a monodominância.

Neste caso, em um processo de recuperação de áreas degradadas, a melhor fase para a introdução de mudas de Brosimum rubescens seria na condição típica de clareiras de pequeno a médio porte (até $100 \mathrm{~m}^{2}$, segundo Brokaw (1982). Além disso, no caso de manejo da floresta, a remoção total do dossel (grandes clareiras) seria prejudicial para o crescimento dessa espécie e para a manutenção da estrutura monodominante da floresta.

\section{Agradecimentos}

Os autores agradecem a todos que auxiliaram no trabalho de campo e viveiro, especialmente a Herson Souza Lima e Edilene Breitenbach. Este estudo foi apoiado pelo PICDT/CAPES e CNPq.

\section{Referências bibliográficas}

Agyeman, V.K.; Swaine, M.D. \& Thompson, J. 1999. Responses of tropical forest tree seedlings to irradiance and the derivation of a light response index. Journal of Ecology 87: 815-827.

Alvarenga, A.A.; Castro, E.M.; Lima Júnior, E.C. \& Magalhães, M.M. 2003. Effects of different light levels on the initial growth and photosynthesis of Croton urucurana Baill. in southeastern Brazil. Revista Árvore 27: 53-57.

Augspurger, C.K. 1984. Light requirements of neotropical tree seedlings: a comparative study of growth and survival. Journal of Ecology 72: 777-795.
Bazzaz, F.A. 1991. Regeneration of tropical forests: physiological responses of pioneer and secondary species. Pp. 91-118. In: A. Gomez-Pompa; T.C. Whitmore \& M. Hadley (eds.). Rain Forest Regeneration and Management. Paris/Carnforth, UNESCO/ Parthenon.

Bazzaz, F.A. \& Pickett, S.T.A. 1980. Physiological ecology of tropical succession: a comparative review. Annual Review of Ecology and Systematics 11: 287-310.

Berg, C.C. 1972. Olmedieae-Brosimeae (Moraceae). Flora Neotropica Monograph 7: 161-209.

Bloor, J.M.G. \& Grubb, P.J. 2004. Morphological plasticity of shadetolerant tropical rainforest tree seedlings exposed to light changes. Functional Ecology 18: 337-348.

Brokaw, N.V.L. 1982. The definition of treefall gap and its effect on measures of forest dynamics. Biotropica 14: 158-160.

Brown, N.D. \& Whitmore, T.C. 1992. Do dipterocarp seedlings really partition tropical rain forest gaps? Philosophical Transactions of the Royal Society of London B 335: 369-378.

Chen, H.Y.H. \& Klinka, K. 1998. Survival, growth, and allometry of planted Larix occidentalis seedlings in relation to light availability. Forest Ecology and Management 106: 169-179.

Chiarello, N.R.; Mooney, H.A. \& Williams, K. 1991. Growth carbon allocation and cost of plant tissues. Pp. 327-366. In: R.W. Pearcy; J. Ehleringer; H.A. Mooney \& P.W. Rundel (eds.). Plant Physiological Ecology. London, Chapman \& Hall.

Clark, D.A. \& Clark, D.B. 1992. Life history diversity of canopy and emergent trees in a neotropical rain forest. Ecological Monographs 62: 315-344.

Claussen, J.W. 1996. Acclimation abilities of three tropical rainforest seedlings to an increase in light intensity. Forest Ecology and Management 80: 245-255.

Connell, J.H. \& Lowman, M.D. 1989. Low-diversity tropical rain forests: some possible mechanisms for their existence. The American Naturalist 134: 88-119.

Denslow, J.S. 1980. Gap partitioning among tropical rainforest trees. Biotropica 12: 47-55.

Denslow, J.S.; Schultz, J.C.; Vitousek, P.M. \& Strain, B.R. 1990. Growth responses of tropical shrubs to treefall gap environments. Ecology 71: 165-179.

Duz, S.R.; Siminski, A.; Santos, M. \& Paulilo, M.T.S. 2004. Crescimento inicial de três espécies arbóreas da Floresta Atlântica em resposta à variação na quantidade de luz. Revista Brasileira de Botânica 27: 587-596.

Ellsworth, D.S. \& Reich, P.B. 1996. Photosynthesis and leaf nitrogen in five Amazonian tree species during early secondary succession. Ecology 77: 581-594.

Felfili, J.M. 1997. Dynamics of the natural regeneration in the Gama gallery forest in central Brazil. Forest Ecology and Management 91: 235-245.

Felfili, J.M. \& Abreu, H.M. 1999. Regeneração natural de Roupala montana Aubl., Piptocarpha macropoda Back. e Persea fusca Mez. em quatro condições ambientais na mata de galeria do Gama-DF. Cerne 5: 125-132.

Felfili, J.M.; Franco, A.C.; Fagg, C.W. \& Sousa-Silva, J.C. 2001. Desenvolvimento inicial de espécies de mata de galeria. Pp. 779-811. In: J.F. Ribeiro; C.E.L. Fonseca \& J.C. SousaSilva (eds.). Cerrado: Caracterização e Recuperação de Matas de Galeria. Brasília, Embrapa/MMA/MAPA.

Felfili, J.M.; Hilgbert, L.F.; Franco, A.C.; Sousa-Silva, J.C.; Resende, A.V. \& Nogueira, M.V.P. 1999. Comportamento de plântulas de Sclerolobium paniculatum Vog. var. rubiginosum (Tul.) Benth. sob diferentes níveis de sombreamento, em viveiro. Revista Brasileira de Botânica 22: 297-301.

Fordyce, I.R.; Eamus, D. \& Duff, G.A. 2000. Episodic seedling growth in Allosyncarpia ternate, a lignotuberous, monsoon rainforest tree in northern Australia. Austral Ecology 25: 25-35.

Fownes, J.H. \& Harrington, R.A. 2004. Seedling response to gaps: separating effects of light and nitrogen. Forest Ecology and Management 203: 297-310. 
Green, J.J. \& Newbery, D.M. 2001. Light and seed size affect establishment of grove-forming ectomycorrhizal rain forest tree species. New Phytologist 151: 271-289.

Hoffmann, W.A. \& Franco, A.C. 2003. Comparative growth analysis of tropical forest and savanna woody plants using phylogenetically independent contrasts. Journal of Ecology 91: $475-484$

Hoffmann, W.A.; Orthen, B. \& Franco, A.C. 2004. Constraints to seedling success of savanna and forest trees across the savannaforest boundary. Oecologia 140: 252-260.

Hoffmann, W.A. \& Poorter, H. 2002. Avoiding bias in calculations of relative growth rate. Annals of Botany 80: 37-42.

Kiama, D. \& Kiyiapi, J. 2001. Shade tolerance and regeneration of some tree species of a tropical rain forest in Western Kenya. Plant Ecology 156: 183-191.

Lima Júnior, E.C.; Alvarenga, A.A.; Castro, E.M.; Vieira, C.V. \& Barbosa, J.P.R.A.D. 2006. Aspectos fisioanatômicos de plantas jovens de Cupania vernalis Camb. submetidas a diferentes níveis de sombreamento. Revista Árvore 30: 33-41.

Marimon, B.S. \& Felfili, J.M. 2000. Distribuição de diâmetros e alturas na floresta monodominante de Brosimum rubescens Taub. na Reserva Indígena Areões, Água Boa-MT, Brasil. Revista Árvore 24: 143-150.

Marimon, B.S. \& Felfili, J.M. 2001. Ethnobotanical comparison of "Pau Brasil" (Brosimum rubescens Taub.) forests in a Xavante Indian and a Non-Xavante community in eastern Mato Grosso state, Brazil. Economic Botany 55: 555-569.

Marimon, B.S. \& Felfili, J.M. 2006. Chuva de sementes em uma floresta monodominante de Brosimum rubescens Taub. e em uma floresta mista adjacente no Vale do Araguaia-MT. Acta Botanica Brasilica 20: 423-432.

Marimon, B.S.; Felfili, J.M. \& Haridasan, M. 2001a. Studies in monodominant forests in eastern Mato Grosso, Brazil: I. A forest of Brosimum rubescens Taub. Edinburgh Journal of Botany 58: $123-137$.

Marimon, B.S.; Felfili, J.M. \& Haridasan, M. 2001b. Studies in monodominant forests in eastern Mato Grosso, Brazil: II. A forest in the Areões Xavante Indian Reserve. Edinburgh Journal of Botany 58: 483-497.

Mazzei, L.J.; Rezende, A.V.; Felfili, J.M.; Franco, A.C.; Souza-Silva, J.C.; Cornachia, G. \& Silva, M.A. 1997. Comportamento de plântulas de Ormosia stipularis Ducke submetidas a diferentes níveis de sombreamento em viveiro. Pp. 64-70. In: L.L. Leite \& C.H. Saito (eds.). Contribuição ao Conhecimento Ecológico do Cerrado. Brasília, Ed. UnB.

Mesquita, R.C.G. 2000. Management of advanced regeneration in secondary forests of the Brazilian Amazon. Forest Ecology and Management 130: 131-140.

Nascimento, C.C.; Garcia, J.N. \& Diáz, M.P. 1997a. Agrupamento de espécies madeireiras da Amazônia em função da densidade básica e propriedades mecânicas. Madera y Bosques 3: 33-52.

Nascimento, M.T.; Proctor, J. \& Villela, D.M. 1997b. Forest structure, floristic composition and soils of an Amazonian monodominant forest on Maracá Island, Roraima, Brazil. Edinburgh Journal of Botany 54: 1-38.

Oberbauer, S.F. \& Strain, B.R. 1984. Photosynthesis and successional status of Costa Rican rain forest trees. Photosynthesis Research 5: 227-232.

Poorter, L. 1999. Growth responses of 15 rain-forest tree species to a light gradient: the relative importance of morphological and physiological traits. Functional Ecology 13: 396-410.
Poorter, L. \& Hayashida-Oliver, Y. 2000. Effects of seasonal drought on gap and understorey seedlings in a Bolivian moist forest. Journal of Tropical Ecology 16: 481-498.

Popma, J. \& Bongers, F. 1988. The effect of canopy gaps on growth and morphology of seedlings of rain forest species. Oecologia 75: 625-632.

Popma, J. \& Bongers, F. 1991. Acclimation of seedlings of three Mexican tropical rain forest tree species to a change in light availability. Journal of Tropical Ecology 7: 85-97.

Press, M.C.; Brown, N.D.; Barker, M.G. \& Zipperlen, S.W. 1996. Photosynthetic responses to light in tropical rainforest tree seedlings. Pp. 41-58. In: M.D. Swaine (ed.). The Ecology of Tropical Forest Tree Seedlings. Paris/Carnforth, UNESCO/Parthenon.

Ramos, K.M.O.; Felfili, J.M.; Fagg, C.W.; Sousa-Silva, J.C. \& Franco, A.C. 2004. Desenvolvimento inicial e repartição de biomassa de Amburana cearensis (Allemao) A.C. Smith, em diferentes condições de sombreamento. Acta Botanica Brasilica 18: 351-358.

Read, J.; Jaffré, T.; Godrie, E.; Hope, G.S. \& Veillon, J.M. 2000. Structural and floristic characteristics of some monodominant and adjacent mixed rainforests in New Caledonia. Journal of Biogeography 27: 233-250.

Reich, P.B.; Ellsworth, D.S. \& Walters, M.B. 1998. Leaf structure (specific leaf area) modulates photosynthesis-nitrogen relations: evidence from within and across species and functional groups. Functional Ecology 12: 948-958.

Rezende, A.V.; Salgado, M.A.S.; Felfili, J.M.; Franco, A.C.; Souza-Silva, J.C.; Cornachia, G. \& Silva, M.A. 1998. Crescimento e repartição de biomassa em plântulas de Cryptocharia aschersoniana Mez. submetidas a diferentes regimes de luz em viveiro. Boletim do Herbário Ezechias Paulo Heringer 2: 19-34.

Richards, P.W. 1996. The Tropical Rain Forest. $2^{\text {nd }}$ ed. Cambridge, Cambridge University Press.

Santos, H.P. \& Buckeridge, M.S. 2004. The role of the storage carbon of cotyledons in the establishment of seedlings of Hymenaea courbaril under different light conditions. Annals of Botany 94: 819-830.

SAS Institute. 1999-2000. The SAS System, for Windows. Carey, NC, USA, SAS Institute.

Sipe, T.W. \& Bazzaz, F.A. 1995. Gap partitioning among maples (Acer) in central New England: shoot architecture and photosynthesis. Ecology 75: 2318-2332.

Sokal, R.R. \& Rohlf, F.J. 1981. Biometry. San Francisco, W.H. Freeman \& Co.

SPSS. 1997. SYSTAT 7.0 for Windows. Statistical Package for the Social Sciences. Chicago, Statistical Product and Service Solutions Inc.

Strauss-Debenedetti, S. \& Bazzaz, F.A. 1991. Plasticity and acclimation to light in tropical Moraceae of different successional positions. Oecologia 87: 377-387.

Swaine, M.D. \& Whitmore, T.C. 1988. On the definition of ecological species groups in tropical rain forests. Vegetatio $\mathbf{7 5}$ : 81-86.

Tabachnick, B.G. \& Fidell, L.S. 2001. Using Multivariate Statistics. New York, Harper Collins Pub.

Torti, S.D.; Coley, P.D. \& Kursar, T.A. 2001. Causes and consequences of monodominance in tropical lowland forests. The American Naturalist 157: 141-153.

Veenendaal, E.M.; Swaine, M.D.; Lecha, R.T.; Walsh, M.F.; Abebrese, I.K. \& Owusu-Afriyie, K. 1996. Responses of West African forest tree species to irradiance and soil fertility. Functional Ecology 10: 501-511. 